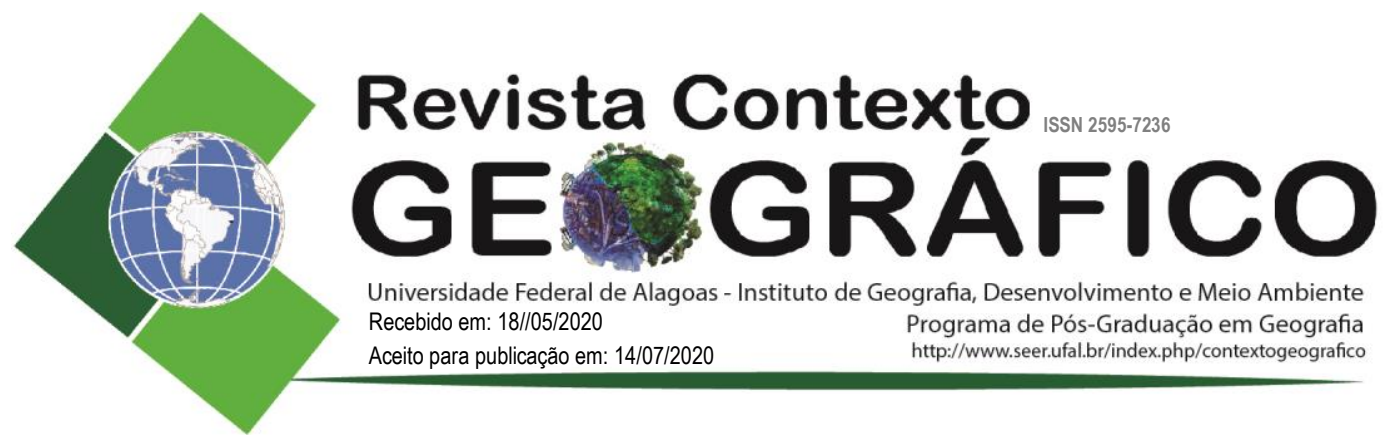

\title{
A GEOGRAFIA ECONÔMICA NO ENSINO DE GEOGRAFIA
}

\author{
Hinckley Wendell do Nascimento Mendes \\ Mestre em Geografia pelo Programa de Pós-Graduação em Geografia da Universidade Federal \\ de Alagoas, Maceió - AL. \\ hinckley.wmendes@gmail.com
}

\begin{abstract}
RESUMO - Este trabalho busca apresentar a importância da geografia econômica na educação básica para fortalecer o entendimento dos discentes sobre a Geografia enquanto ciência. O objetivo deste artigo é analisar o papel da geografia econômica para que se compreenda a importância da Geografia na educação básica. Para melhor compreender este artigo, existem dois objetivos específicos: entender como a geografia econômica une as duas vertentes de análise da Geografia, a Geografia Humana e Geografia Física; e o segundo objetivo, é compreender a Geografia como ciência fundamental ao desenvolvimento e progresso da humanidade. Para realização deste trabalho utiliza-se os seguintes procedimentos metodológicos: pesquisas bibliográficas sobre o ensino da Geografia e a geografia econômica, encontrados nos sites acadêmicos do Ministério da Educação, UFSC, Scielo, entre outros Assim, o artigo apresenta a relevância da geografia econômica no ensino da Geografia, principalmente para professores e discentes da educação básica.
\end{abstract}

Palavras-chave: Professores de geografia; Educação básica; Combinações geográficas.

\section{LA GEOGRAFÍA ECONÓMICA EN LA ENSEÑANZA DE LA GEOGRAFÍA}

\begin{abstract}
RESUMEN - Este artículo busca presentar la importancia de la geografía económica en la educación básica para fortalecer la comprensión de los estudiantes de la Geografía como ciencia. El propósito de este artículo es analizar el papel de la geografía económica para comprender la importancia de la geografía en la educación básica. Para comprender mejor este artículo, hay dos objetivos específicos: comprender cómo la geografía económica une los dos aspectos del análisis de la geografía, la geografía humana y la geografía física; y el segundo objetivo, es entender la Geografía como una ciencia fundamental para el desarrollo y el progreso de la humanidad. Para llevar a cabo este trabajo, se utilizan los siguientes procedimientos metodológicos: investigación bibliográfica sobre la enseñanza de Geografía y geografía económica, que se encuentra en los sitios web académicos del Ministerio de Educación, UFSC, Scielo, entre otros. Así, el artículo presenta la relevancia de la geografía económica en la enseñanza de la geografía, principalmente para profesores y estudiantes de educación básica.
\end{abstract}

Keywords: Profesores de geografía; Educación básica; Combinaciones geográficas.

\section{INTRODUÇÃO}

Para os geógrafos (licenciados e bacharéis), não há dúvidas sobre objeto de estudo da Geografia, mas ainda é necessário falar desta ciência para todas as classes, em especial as secundaristas, pois a Geografia faz parte da Base Nacional Comum Curricular (BNCC). Embora esta ciência tenha passado por várias transformações ao longo dos anos, sendo ela fragmentada em duas frentes de análise, Geografia Humana e a Geografia Física, não se pode negar que ela foi 
definitivamente a ciência que mais contribuiu com a expansão e aproximação de nações ao longo dos últimos séculos. É por esta razão, que a Geografia continua a ser uma ciência fundamental para o desenvolvimento da humanidade, portanto, essencial ao ensino básico.

Para compreender a importância da Geografia na educação básica, é necessário apresentar que embora organizada em duas vertentes de análises, elas não são distintas, mas dependentes uma da outra. Enquanto a Geografia Humana se preocupa em analisar elementos voltados a ocupação do homem na Terra, a Geografia Física, analisa elementos voltados a formação de fenômenos físicos e biológicos. Além disso, a Geografia possui alguns ramos, que estudam problemas específicos, e entre eles, encontra-se a geografia econômica. Entre os elementos de estudos da geografia econômica, podemos compreender a relação: matéria-prima, industrialização e consumo e, também, como essas atividades influenciam no espaço geográfico.

Por meio da geografia econômica, os alunos de educação básica podem compreender o espaço em que estão inseridos sob a ótica geográfica. Existem duas hipóteses neste artigo, a primeira é que a geografia econômica quando analisa a Geografia levando em consideração as combinações geográficas, fortalece a compreensão do todo geográfico. E a segunda, entende que a relação da geografia econômica com elementos do cotidiano dos alunos, facilita a compreensão sobre a importância da Geografia no ensino.

Levando em consideração esses aspectos, o objetivo deste artigo é analisar o papel da geografia econômica para que se compreenda a importância da Geografia na educação básica. Dois são os objetivos específicos deste trabalho. O primeiro, é entender como a geografia econômica une as duas vertentes de análise - Geografia Física e Geografia Humana. Enquanto o segundo objetivo, compreende a Geografia como ciência fundamental ao desenvolvimento e progresso da humanidade.

O desenvolvimento deste trabalho possui relevância para a comunidade acadêmica, professores e estudantes de educação básica. Já existem diversos trabalhos que discutem o ensino da Geografia nas escolas, mas ainda são mínimos os que discutem o papel da geografia econômica na educação básica. E esta por sua vez, tem uma capacidade de relacionar conhecimentos da Geografia Física e Geografia humana, mostrando que ambas fazem parte uma única Geografia. Pensando nesse fato, o artigo discute a sua relevância para o ensino da Geografia.

\section{METODOLOGIA}

A realização deste trabalho ocorreu por meio de pesquisas bibliográficas sobre o ensino da Geografia e a geografia econômica. Como principal referencial teórico, mostra-se as combinações geográficas de Cholley (1964a/1964b), além de artigos bibliográficos sobre o pensamento geográfico, ensino da Geografia e abordagens sobre geografia econômica. Os procedimentos adotados foram: leitura e análise dos materiais bibliográficos encontrados em sites acadêmicos (MEC, Scielo, UFSC e outros); e por fim, construção do artigo para compreensão do tema.

\section{O ENSINO DA GEOGRAFIA}

A Geografia estabeleceu importantes conexões a partir das conquistas territoriais, dando ao mundo novas configurações espaciais. Á medida que novos lugares eram explorados, novas características naturais e culturais foram notadas e foi a partir dessas descobertas que a Geografia passou a ser utilizada como instrumento de análise importante, sobretudo para apresentar todos os elementos presentes na Terra. Embora no sentido etimológico, a Geografia signifique "descrição da Terra", ela não pode ser interpretada como tal, pois envolve uma série de processos históricos, sociológicos, filosóficos, biológicos, físicos, químicos, entre outros, que dão características originais à Geografia. 
Esses elementos fazem da Geografia, ciência fundamental para toda humanidade, pois é através dela que podemos observar o mundo e seus objetos a partir do lugar que estamos inseridos. Esse fato, fez com que a Geografia fizesse parte dos projetos de formação escolar e das políticas públicas para a educação (NOGUEIRA, 2015). Assim, o ensino da Geografia passou a ser utilizado nos períodos iniciais de formação dos indivíduos para que se conheçam o mundo a partir do lugar que vivem.

Na BNCC, o componente curricular da Geografia, compõem a área de ciências humanas, isto leva a determinados alunos à conflitos sobre qual o objeto de estudo e a função da Geografia, enquanto disciplina escolar, tendo em vista que nela não se encontram apenas elementos voltados aos estudos humanos, como são as demais disciplinas que compõem a área. Segundo Nogueira (2015, p. 04), "a despeito de sua especificidade curricular, traz como elemento norteador as relações cotidianas que se passam nos lugares, nas regiões e no mundo".

Entender o mundo, envolve a compreensão sobre o passado e o presente para que se compreenda os caminhos adotados para o futuro. Para isso, é necessário recorrer a história, economia, biologia, sociologia, física, entre outros. Sendo o mundo em que vivemos, composto por todos essas ciências, é através da Geografia que os alunos de educação básica, são esclarecidos da relação dessas ciências com sua vida.

De acordo com a proposta dos Parâmetros Curriculares Nacionais, a Geografia tem um tratamento específico como área, pois ela oferece instrumentos essenciais para a compreensão e intervenção na realidade social. Por meio dela, os alunos em formação, conseguem compreender como diferentes sociedades interagem com a natureza na construção de seu espaço, além de identificar as singularidades do lugar em que vivem, conseguindo diferenciar e aproximar sua relação com outros lugares e adquirir uma consciência maior dos vínculos afetivos e de identidade do Mundo em que vivemos. Assim, através da Geografia, é possível conhecer as múltiplas relações de um lugar com outros lugares, distantes no tempo e no espaço e perceber as relações do passado com o presente (BRASIL, 1998).

Segundo Pereira (1988, p.12), inclui-se a geografia nos currículos por razões geopolíticas, pois além de marcar a naturalidade do homem no espaço, ela sustenta que o homem só é humano, porque está incluso em um espaço nacional e politizado. A geografia analisa o físico, mas esse estudo, não terá sentido se o homem não for considerado em um espaço em que se exerce uma determinada cidadania.

Entende-se que a Geografia é uma ciência humana, entretanto é por meio dela que se estabelecem ligações entre os aspectos históricos e sociais, físicos, químicos e biológicos. Desta forma, a Geografia encontra sua função não só na educação básica, mas no dia a dia da humanidade.

\section{AS COMBINAÇÕES GEOGRÁFICAS E A GEOGRAFIA ECONÔMICA}

Segundo Mamigonian $(2019$, p. 7) "a geopolítica e a geografia econômica foram importantes ao longo do século XIX e XX na busca do conhecimento dos problemas mundiais, nacionais e regionais." Esses dois ramos da Geografia são pontes importantes, pois não desassociam o físico e o humano e conseguem compreender que tanto o conhecimento de Geografia Física, como de Geografia Humana, é indissociável. Um método bastante utilizado para compreender a importância de todos os ramos da Geografia, são as combinações geográficas.

O estudo das combinações geográficas se mostra importante por explicar o caráter original da Geografia, ainda que esta possua ramos diferentes. Dentro desta concepção, entende-se que a geografia econômica é capaz explicar aos discentes do ensino básico, o porquê da Geografia estudar elementos naturais e humanos em conjunto. 
As combinações geográficas foram concebidas por Vidal de La Blache ${ }^{1}$, mas desenvolvida como ideia central por André Cholley (1964a;1964b), que explica o papel das múltiplas determinações na sociedade e no espaço. Para o autor, as combinações geográficas explicam o caráter original das análises geográficas, pois, diferente das outras ciências, a Geografia não analisa os fatos isoladamente, ela atua em duas dimensões "tempo e espaço". Esse duplo caráter, garante a originalidade da Geografia, que se dá pela análise e interpretação de todas as combinações existentes na superfície do globo.

Cholley (1964b) aponta que a Geografia utiliza dois métodos, o natural e histórico. O das ciências naturais, interpreta combinações que estão em movimento e em ação no espaço que ocupa; já o método histórico, permite reconstituir as sucessões e as substituições de combinações que ocorreram em um ponto da superfície da Terra, ele reúne acontecimentos que se desenrolaram no passado auxiliam a compreender ações do presente. A utilização dos dois métodos, permite interpretar a realidade da Terra, seja por meio do viés natural ou histórico, "cabe-nos saber qual método melhor convém para chegar atingir o processo espacial das combinações" (CHOLLEY, 1964b, p. 268).

Desse modo, a Geografia utiliza as combinações como objeto de estudo determinando as suas características a partir das razões de convergência dos elementos existentes no globo. Além disso, as combinações geográficas oferecem uma localização especial e se manifestam na superfície da Terra, pois é onde os elementos das combinações entram em contato e se manifestam.

"A própria estrutura das combinações nos impede de considerar isoladamente os fatores que as compõem, isto é, eles existem somente como elementos da combinação e nas combinações de que fazem parte que convém apreciá-los" (CHOLLEY, 1964a, p. 139;1964b, p. 267).

Para desvendar o caráter geográfico de uma combinação, cabe verificar se ela contribui para criar, no próprio local em que se produz um meio particular que possibilite a manifestação da vida, em especial as que apresentam atividades dos grupos humanos (CHOLLEY, 1964a, p.140). As combinações podem ser divididas em três importantes categorias: físicas, biológicas e humanas. As combinações físicas dão características as estruturas internas da Terra, é nessa combinação que são identificados elementos ligados mais a estrutura da Terra, como os elementos edafoclimáticos. As biológicas são dependentes das combinações físicas, esta é responsável pelas características fisiográficas e a forma como os animais e vegetais se adaptam geograficamente a um determinado local. Contudo, as combinações humanas, mais abstrusas, criam seus próprios meios de sobrevivência e métodos (cultura, infraestrutura, política e organização social) que não dependem exclusivamente das forças naturais (CHOLLEY, 1964a; 1964b).

Cada uma dessas combinações provocou certo tipo de povoamento do solo, criou uma estrutura social mais ou menos diferenciadas, determinou uma forma de organização da terra, fez, mesmo surgir focos regionais por um gênero de vida bem característicos (CHOLLEY, 1964a, p. 141-142).

Por isso, as combinações geográficas estão relacionadas com a geografia econômica, pois este ramo da Geografia vai entender as estruturas produtiva da sociedade e como criam-se meios de se organizar no espaço. Embora, as combinações físicas e biológicas, sejam importantes, pois elas dão características naturais a possibilidade de desenvolver atividades econômicas e sociais, elas não definem a evolução da humanidade. São as combinações humanas que possibilitam maior interferência nas combinações físicas e biológicas, e é através dessa interferência que ocorrem progressos na humanidade. Afinal, é por meio da realização de atividades necessárias à vida dos grupos humanos, que se criam sistemas de produção agrícolas, indústrias etc., capazes de resolver os problemas enfrentados pela sociedade (CHOLLEY, 1964a). 


\section{A IMPORTÂNCIA DA GEOGRAFIA ECONÔMICA NO ENSINO DA GEOGRAFIA}

Segundo Araújo Jr. (2015), a Geografia torna-se ciência, em meio a expansão do Estados nacionais na Europa, durante a segunda metade do século XIX. O avanço do modo de produção capitalista a partir das duas Revoluções Industriais no século XVIII e XIX, serviu como base teórica de reprodução ideológica e política no ensino de geografia. Num primeiro momento, a Geografia era essencialmente descritiva dos aspectos físicos (formas do relevo, hidrografia etc.) e pouco relacionava atuação humana na natureza (população, atividades econômicas, entre outros fatores). Na atualidade, existe uma maior exigência de escolaridade no setor produtivo, em função das necessidades do grande capital internacional (e nacional), que requer mão de obra mais qualificada para a introduzir inovações tecnológicas em suas respectivas unidades produtivas.

Isto, levou o ensino da geografia a focar em análises que sirvam aos interesses do capital, como por exemplo: análise dos planejamentos ambientais, urbanos e rurais e das tecnologias (cartografia, geoprocessamento), além do conhecimento geográfico sobre o território e o espaço mundial. Entretanto, no Brasil, a tradição do ensino de geografia, principalmente no ensino fundamental e médio, trata esta ciência com um forte viés descritivo, principalmente do meio físico. Além do mais, quando "há um discurso e prática da observação e descrição dos lugares, retira-se a conotação política sobre o entendimento das transformações verificadas ao longo da história", ou seja, pouco ou quase nada existe de análise crítica dos processos que levaram a transformação da sociedade e do espaço (ARAÚJO JÚNIOR, 2015).

Ainda de acordo com Araújo Junior (2015, p. 143) apud Brabant (1998, p. 18), esta predileção da geografia escolar pela geografia física encontra também suas raízes na geografia dos militares. [...] "O militar tem necessidade de fazer o inventário de todos os dados úteis ou potencialmente úteis para armazenar as informações suscetíveis de servir-lhe para o futuro [...]". Esse discurso descritivo, e por vezes determinista, elimina, na sua forma constitutiva, toda a preocupação de explicação. "A primeira preocupação é descrever em lugar de explicar; inventariar e classificar em lugar de analisar e de interpretar" (p.18).

A Geografia enquanto disciplina tem o papel de não apenas localizar, identificar e caracterizar os elementos que existem no espaço, pois, embora sejam importantes, não são o suficiente para contribuir com as análises geográficas. Para que uma análise seja geográfica, é necessário compreender as interação entre os fenômenos existentes na natureza e no espaços enecúmenos, afinal, é partir da interação de fenômenos encontrados na natureza e nas relações humanas, que existem combinações geográficas que permitem o desenvolvimento de atividades humanas.

De acordo com Santos (2000, p. 104), a ideia da geografia como disciplina das localizações, é limitada, no que se trata das relações que se dão entre o homem e o meio e, por essa razão, revela-se insuficiente. A riqueza da Geografia reside, justamente, no fato de que podemos pensar, a um só tempo, os objetos (a materialidade) e as ações (a sociedade) que estão presentes no espaço. "As demais ciências humanas não dominam esse rico veio epistemológico" (SANTOS, 2000, p. 104).

No ensino da geografia, não é tão frequente a consideração da totalidade do conhecimento geográfico. "A Geografia é quase sempre apresentada ao estudante, desde o primeiro momento, de forma segmentada, dificultando a apreensão de uma abordagem essencialmente geográfica" (SANTOS, 2000, p. 105). Para o autor, a Geografia não deve ser ensinada apenas no que tange um ramo específico, mas em sua totalidade, a Geografia é Física e é Humana, esta é a totalidade da Geografia, que entende que o homem, ao interagir com a natureza, transforma o espaço e torna a Geografia disciplina fundamental para formação de sujeitos críticos.

Santos (2013, p. 51) afirma que existe uma multiplicidade de "geografias", mas elas não representam fraqueza a Geografia unificada, quando analisam mecanismos particulares que contribuem com a compreensão dos mecanismos gerais. Isto é, há análises e métodos 
específicos na Geografia Humana e na Geografia Física, mas elas são convergentes quando se encontram o mecanismo geral: Relação homem e natureza.

Analisar a Geografia dentro de uma totalidade, não ignora o fato de que existem diferentes ramos de análise nesta ciência: geografia regional, urbana, agrária, climatologia, biológica, cartografia e econômica, etc., mas cada uma delas possuem análises especificas e suas interpretações levam em consideração o papel do homem no globo terrestre. Todavia, entre os ramos da geografia que interpretam o papel do homem na natureza, a geografia econômica se destaca.

De acordo com Mamigonian e Bastos (2008), "a geografia econômica é um enorme cruzamento de geografia, história e economia". Levando em consideração a importância da geografia econômica, o aluno vai entender que o desenvolvimento dos países, dentro de um mundo globalizado, segue determinações da Divisão Internacional do Trabalho (D.I.T). Vale ressaltar, que os recursos naturais são fundamentais para que o homem busque formas de utiliza-los para sobreviver ou desenvolver atividades econômicas, pois o mundo tal como conhecemos, é dividido em exportadores de matérias-primas, com baixa capacidade de inovação tecnológica e países com alta capacidade de tecnologia que acabam sobressaindo sobre países que são condicionados a importar produtos industrializados.

A análise da industrialização e do desenvolvimento tecnológico, também passam pelas análises da geografia econômica, afinal para garantir a sobrevivência e a longevidade, criam-se formas de adaptação do homem a todo, ou pelo menos quase todos, empecilhos naturais. Garantindo assim, possibilidades de progressos alimentícios, farmacêuticos, medicinais, comunicativos, entre outros.

Para Araújo Junior (2015), o papel da Geografia é desenvolver no aluno sua capacidade de observar, refletir, interpretar e analisar criticamente a realidade considerando sua transformação e essa realidade envolve a relação entre sociedade e natureza. Através da Geografia, compreende-se o espaço produzido, a apropriação que a sociedade faz sobre a natureza e as contradições e dicotomias existentes nessa relação.

"Isso está implícito nas relações entre os homens que produzem o espaço transformado, pois sua organização é também reflexo da divisão social em diferentes períodos históricos, numa perspectiva dinâmica" (ARAÚJO JÚNIOR, p.146).

Deste modo, o ensino de Geografia - e em particular a geografia econômica - deve considerar a complexa relação da sociedade com a natureza e dos homens em sociedade. É partindo desta perspectiva, que os alunos se aproximam de uma imagem territorial, independentemente de sua localização e vão passar a compreender a diversidade de complexidades existentes no espaço.

Desde Humboldt e Ritter a geografia estuda toda a superfície da Terra, tentando decifrar os fenômenos da natureza e da sociedade. Para cumprir esta tarefa enorme é obrigada a reconhecer as diversas escalas nas quais estes fenômenos se manifestam. Desde a Antiguidade os gregos haviam percebido que a natureza tem uma delimitação mais ampla em zonas climáticas, mas também constataram uma delimitação menor e muito importante no que se refere às planícies fluviais e às áreas montanhosas, claramente visíveis no Mediterrâneo. Observações importantes, que ajudaram a orientar os estudos sobre a natureza realizados posteriormente. Com a expansão do capitalismo as diferentes sociedades humanas espalhadas pelo mundo foram sendo conectadas e assim foi possível ir reconhecendo nos últimos séculos a existência de uma escala mundial, além de escalas nacionais e regionais como espaços distintos, mas interligados. (MAMIGONIAN, 2019, p. 40). 
Desde sua gênese a Geografia mostra-se como ciência fundamental e indispensável a organização da humanidade e continua sendo relevante a educação básica. Atualmente, é necessário compreender que tudo estar interligado, não há como falar da cidade local, sem pensar o mundo; não há como falar de Amazônia ou do agronegócio, sem pensar as ações humanas no espaço físico; não há como falar de industrialização, sem pensar no êxodo rural; não há como falar de globalização, sem pensar em neoliberalismo; não há como falar de conflitos étnicos, sem pensar em território e geopolítica global. Na educação básica, os discentes precisam compreender que a Geografia é utilizada por eles em seu dia a dia, todos os elementos, todas as tecnologias, todas informações que recebem e todas as formas como se organizam, é resultado de estruturas presentes no espaço mundial e é a Geografia que busca explicar todos os processos existentes no globo terrestre, pois nele existem agentes físicos, biológicos e humanos (sociais, econômicos e políticos).

Compreender o espaço geográfico é saber que esse espaço é modificado pelas relações existentes entre homem e natureza. Na ocasião, a geografia econômica, estabelece melhor essas relações, pois não é um ramo matemático da geografia, muito menos um ramo sociológico, é um ramo capaz de compreender que o espaço geográfico só existe por ser transformado por atividades capazes mudar as condições de vida da humanidade.

\section{CONSIDERAÇÕES FINAIS}

A geografia econômica considera importância das combinações geográficas, em especial as combinações humanas, pois através delas o homem interfere na natureza para organizar atividades agrícolas e industriais capazes de promover desenvolvimento de atividades econômicas.

A partir da intervenção humana sob a natureza que as atividades econômicas ocorrem. Isto, faz os alunos compreenderem que o papel da Geografia não é apenas ensinar a localizar, identificar e caracterizar quantitativamente os fenômenos, é analisar as razões que levam os seres humanos a transformar o espaço com objetivo de atender suas necessidades. Levando em consideração esses aspectos, a geografia econômica, une a Geografia Física e Geografia Humana, como uma só Geografia.

Este ramo da Geografia aborda sobre o papel dos seres humanos interferindo na natureza com objetivo de obter algum tipo de benefício. Outros ramos como urbana, agrícola, regional, climatologia, cartografia, geoprocessamento etc., recebem influência da geografia econômica, que desempenhou como função compreender a ação do homem na natureza para criar condições de desenvolvimento em terras produtivas ou não produtivas. Tudo isso, só é possível, primeiramente por conta do conhecimento do homem sobre a natureza, e posteriormente, pela criação de tecnologias capazes de gerar transformações socioespaciais.

\section{REFERÊNCIAS}

Araújo Junior, Aloysio Martins de. Geografia econômica: pesquisa e ensino na ação docente. Florianópolis: Edições do Bosque/CFH/UFSC, 2015. 432 p.: graf., tabs. (Série Sociedade e Meio Ambiente).

BRASIL. Ministério da Educação. Parâmetros Curriculares Nacionais: Geografia. Secretaria de Educação Fundamental. Brasília: MEC/SEF. 1998.

CHOLLEY, André. Observações sobre alguns pontos de vista geográficos. Boletim Geográfico. N 179:3 mar-abr, 1964a. 
<biblioteca.ibge.gov.br/visualizacao/periodicos/19/bg_1964_v22_n179_mar_abr.pdf>. Acesso em 27/03/2018.

CHOLLEY, André. Observações sobre alguns pontos de vista geográficos. Boletim Geográfico. $\mathrm{N}^{\circ}$ 180:3 mai-jun, 1964b.

https://biblioteca.ibge.gov.br/visualizacao/periodicos/19/bg_1964_v22_n180_maio_jun.pdf> Acesso em 28/03/2018.

GEOGRAFIA ECONÔMICA - Anais de Geografia Econômica e Social: Mundo, Brasil, Regiões, GEOGRAFIA ECONÔMICA, Florianópolis Edição nº 1 - Revisada 349 p. Julho, 2008, ISSN 1983-4543. Org: MAMIGONIAN, Armen Mamigonian; BASTOS, José Messias.

MAMIGONIAN, Armen. Visão geográfica do Brasil atual: estado, crises e desenvolvimento regional. Revista Latino - Americana de Geografia Econômica e Social, Foz do Iguaçu, v. 01, n. 1, p. 007-044, Jul/Dez, 2019

NOGUEIRA, Amélia Regina Batista. Componente Curricular Geografia e a Base Nacional Comum Curricular. Base Nacional Comum Curricular, 2015. Disponível em: $<$ http://basenacionalcomum.mec.gov.br/images/relatoriosanaliticos/Amelia_Regina_Batista_Nogueira.pdf>. Acesso em: 15/02/2020.

PEREIRA, Raquel Maria Fontes do Amaral. Da Geografia que se ensina à gênese da Geografia moderna. Florianópolis-SC: UFSC, Programa de Pós-graduação em Educação, 1988.

RABANT, Jean-Marie. crise da geografia, crise da escola. In: OLIVEIRA, Ariovaldo Umbelino de (Org.). Para onde vai o ensino de geografia? 6. ed. São Paulo: Contexto, 1998 (Coleção Repensando o Ensino) apud Araújo Junior, Aloysio Martins de. Geografia econômica: pesquisa e ensino na ação docente, Florianópolis: Edições do Bosque/CFH/UFSC, 2015. 432 p.: graf., tabs. (Série Sociedade e Meio Ambiente).

SANTOS, Milton. O papel ativo da Geografia: um manifesto. XII Encontro Nacional de Geógrafos Florianópolis - julho de 2000.

SANTOS, Milton. O trabalho do Geógrafo no Terceiro Mundo. 5 a ed. - São Paulo: Editora da Universidade de São Paulo, 2013. 136p.

${ }^{1}$ LA BLACHE, Vida. As características próprias da Geografia. CHRISTOFOLETTI, Antônio (Org.). Perspectivas da Geografia. São Paulo: DIFEL, 1982. p. 37-47 